\title{
Review of Nuclear Waste Isolation
}

\author{
B. H. Richard, Editor
}

\section{June 1978}

Prepared for the United States

Department of Energy

Under Contract EY-77-C-06-1030

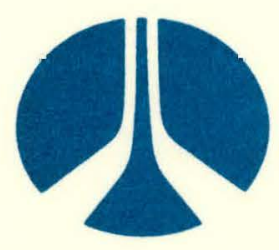

\section{Rockwell International}

Rockwell Hanford Operations

Energy Systems Group

Richland, WA 99352 


\section{DISCLAIMER}

This report was prepared as an account of work sponsored by an agency of the United States Government. Neither the United States Government nor any agency Thereof, nor any of their employees, makes any warranty, express or implied, or assumes any legal liability or responsibility for the accuracy, completeness, or usefulness of any information, apparatus, product, or process disclosed, or represents that its use would not infringe privately owned rights. Reference herein to any specific commercial product, process, or service by trade name, trademark, manufacturer, or otherwise does not necessarily constitute or imply its endorsement, recommendation, or favoring by the United States Government or any agency thereof. The views and opinions of authors expressed herein do not necessarily state or reflect those of the United States Government or any agency thereof. 


\section{DISCLAIMER}

Portions of this document may be illegible in electronic image products. Images are produced from the best available original document. 


\title{
Q
}

\section{Rockwell International}

Rockwell Hanford Operations

Energy Systems Group

Richland, WA 99352

\begin{abstract}
PREPARED FOR THE UNITED STATES DEPARTMENT OF ENERGY
\end{abstract}
UNDER CONTRACT EY-77-C-06-1030

\section{PRELIMINARY REPORT}

This Report contains information of a preliminary nature. It is subject to revision or correction and therefore does not represent a final Report. It was prepared primarily for internal use within The Rockwell Hanford Operations. Any expressed views and opinions are those of the Author and not necessarily of the Company.

\section{NOTICE}

This Report was prepared as an account of work sponsored by the United States Government. Neither the United States nor the United States Department of Energy, nor any of their Employees, nor any of their Contractors, Subcontractors, or their Employees, makes any warranty, express or implied, or assumes any legal liability or responsibility for the accuracy, completeness, or usefulness of any information, apparatus, product or process disclosed, or represents that its use would not infringe privately owned rights. 
B. H. Richard, Editor

for

Basalt Waste Isolation Program
June 1978

Rockwell International

Rockwe 11 Hanford Operations

Energy Systems Group

Richland, Washington 99352
This report was preporice

This report was prepared as an eccount of work

sponsored hy the Unitod Siatcs Qurem ment. Neither the

Energy, nor any of Uniced States Department of

Energy, nor any of their employees, not suly of their

any

liajly or express or implied, of assumes any legal

lab iny of resporisibility for the accuracy, completenes

process diss of any information, apparatus, product or

infius prtwated, or represents that its use wnuld not

infininge prtvately owned rights. 
TABLE OF CONTENTS

INTRODUCTION
SUMMARY STATEMENT
$\begin{aligned} & \text { Page } \\ & \text { REPORTS OF WORKSHOPS }\end{aligned}$
PATHS OF TRANSPORT TO THE BIOSPHERE
BARRIERS NEEDED FOR CONTAINMENT
TIME OF ISOLATION FROM THE BIOSPHERE
FOR EACH RADIOACTIVE ISOTOPE
$\begin{aligned} & 9 \\ & \text { DISTRIBUTION }\end{aligned}$
APPENDIX A - LIST OF PARTICIPANTS
APPENDIX B - AGENDA




\section{INTRODUCTION}

On June 22 and 23, 1978, Rockwell Hanford Operations assembled a committee of their personnel, subcontractors, and representatives of other waste isolation programs for a review of nuclear waste isolation. Appendix $A$ lists the participants and their affiliations; Appendix $B$ indicates the agenda.

The purpose of the review was to gather experts in the areas pertaining to isolation of nuclear waste to discuss three basic issues that must be addressed in isolation studies. These were:

- The paths of transport to the biosphere;

- The barriers needed for containment;

- The isolation time necessary for each radioactive isotope.

In that these issues are media dependent, the basalt medium was emphasized.

Conclusions of the review are described on the following pages. 


\section{SUMMARY STATEMENT}

R. A. Deju, Basalt Waste Isolation Program Director

\section{PATHS OF TRANSPORT TO THE BIOSPHERE}

The committee, looking at pathways and transport mechanisms to man, carefully analyzed the pathways through which contaminants could potentially move away from a repository. Their discussions indicated that the main emphasis should be placed on understanding the local characteristics of the horizon where the repository is to be contained; namely, the low-permeability, dense basalts, and any potential maninduced effects related to construction activities for such a repository. The second priority is to analyze the environment immediately adjacent to boreholes and shafts, with emphasis on analysis of these boreholes and shafts as potential transport avenues. Finally, as a third priority, characterization of the aquifers overlying and underlying potential repository horizons should be undertaken.

The committee concluded that the processes that could potentially transport radioactive nuclides from a repository were: (1) convection; (2) sorption; and (3) hydrodynamic dispersion/transport in the gas phase/molecular diffusion. Convection received the highest priority, with sorption being the number two priority. It was noted in the discussion that sorption should be completely understood because of its importance as a retarding mechanism for transport of radionuclides.

Specific recommendations of this committee included:

- Preparation of a standard reference basalt sample;

- Determination of regional hydrologic parameters;

- Estimation of hydrologic parameters, such as permeability, etc.;

- Testing in holes through the arca of study;

- Completion of sorption experiments;

- Drilling and testing of slanted holes and horizontal holes as appropriate;

- A balance between core and rotary hole drilling as appropriate;

- Physical and chemical characterization of borehole environments with possible tracer tests, especially for understanding site-specific horizon characteristics; 
- Integration of the impact of thermal stresses on the hydrologic regime;

- Parametric and sensitivity studies to be utilized for prioritizing potentially important phenomena that may affect the repository.

The above areas of study were not prioritized by the committee. All of these have been made part of our program and are being actively investigated. From a management standpoint, we have decided to look at all the above transport processes and characterize the paths to the biosphere inasmuch as possible by utilizing existing techniques with full reliance on such existing technology for their complete assessment.

In parallel with such programs, we are also undertaking and will entertain additional proposals regarding potential research areas that may allow us to better improve our understanding of these transport processes and their impact on a potential repository. The minimization of transport and maximization of retardation are most important to long-term waste isolation.

\section{BARRIERS NEEDED FOR CONTAINMENT}

In the area of containment barriers, the committee discussed the overall levels of containment needed and the various points at which barriers could be emplaced, with emphasis on the improvements that engineering barriers would have on the overall waste isolation. The final goal is that radionuclides should not reach the biosphere in excess of maximum permissible concentrations.

From a standpoint of waste form, present considerations are to look at spent unreprocessed fuel. Some consideration should continue to be given to other waste forms in the event decisions are made that change the present policy. However, emphasis continues to be made on studies of spent unreprocessed fuel. Some research programs should identify and optimize the waste form. Studies are needed to fully determine material properties of spent unreprocessed fuel, phase characteristics, leaching, and potential problems that could occur from their emplacement. All these problems should be analyzed from a standpoint of long-term waste isolation.

The comitimitee telt that containers could be produced with a life in excess of 50 years and that they could do more than handle the waste. 
Materials like hot-pressed alumina, copper, nickel-stainless steel alloys, and nickel-iron alloys may show promise. The committee emphasized that the knowledge and understanding of materials found in nature may lead to a guarantee of isolation for long periods of time. The overpack was also regarded as a containment barrier. Many materials for overpacks are available which could be utilized as very acceptable barriers for long periods of time.

The overpack should be designed to minimize solubility of the waste form from ground water intrusion and provide for corrosion prevention, release of stress, and heat transfer. The impact of the ground water, thermal stresses, and canister emplacement techniques on the overnack. must also be studied. The committee concluded that the effect of canister improvements, optimization of waste forms (if spent unreprocessed fuel is not regarded as the final waste forml, and development of adequate overpacks could improve safety of the final waste isolation process.

The committee also looked at borehole plugging as a barrier to the biosphere. Materials need to be studied which are easily emplaced, are of low permeability, and are adequately bound to the host rocks with a great deal of physicochemical stability. Many materials show such promise. The committee looked at the basalt host rock from the standpoint of being the final barrier to transport. Models to show the interaction between the host rock, the waste, and the engineered improvements are presently needed and should be developed.

Overall, the majority of the committee felt that the combination of engineering barriers with favorable host rock properties and functions to optimize waste isolation show great promise.

As part of our effort at Hanford, we are attempting to study wastebasalt interactions as part of our technology development program, and the engineering barrier as part of repository design. We hope that a combination of research and development and utilization of present know?edge will lead to an acceptable design for a potential repository.

\section{TIME OF ISOLATION FROM THE BIOSPHERE FOR EACH RADIOACTIVE ISOTOPE}

The committee, while discussing time of containment, concluded that the overall time for isolation must be determined from parameters established for each specific site and by conducting various studies for 
a give medium at a given site. The isolation time for each nuclide will depend upon its initial concentration and acceptable dose to man. A number of important parameters must be considered:

- Quantity of nuclides in the repository;

- Container lifetime;

- Fluid velocity;

- Path length;

- $K_{d}$ adsorption;

- $k_{d}$ desorption;

- Maximum permissible concentrations to the biosphere;

- Leach rate for each isotope for the assumed waste form.

These parameters need to be gathered and can then be used to determine the relative importance of containment of a given nuclide under given site-specific conditions. Once travel times for each isotope are established for transport to the biosphere from specific repository horizons, the necessary degree of isolation can be established. If isolation of a given isotope is deemed adequate, the dimensions in the natural parameters can be changed or the engineered parameters can be improved. It appears possible that the dose of a given isotope can be retarded by engineered parameters and/or geometric considerations such that the dose will be less than the maximum permissible level throughout all time. The committee concluded that studies should be conducted to examine the relationship between modeling, data gathering, and time extrapolation. Studies should be conducted in the following order:

- Existing data should be.used to develop a simplistic model of the repository area relating travel time to the biosphere with the identified parameters;

- Gather additional data based on information and direction gained from the first model;

- Develop more detailed models based on the additional data;

- Run scenario studies to verity or modify these models;

- Take these results to extrapolate time into the future.

The confidence level of the final model will establish the confidence of the time prediction.

Retrievability was also considered by the committee. It need not be considered critical for isolation times in basalt. The committee was reasonably confident about being able to keep a container intact for over 
hundreds of years, since mines in similar rocks have been operated for over 100 years, although under different conditions.

Finally, the issue of predictability was discussed. Short time predictions are a function of engineered characteristics and waste-rock interactions tests. Long time predictions are a function of knowledge of the geologic past and the ability to use these data to project into the future. 
REPORTS OF WORKSHOPS 


\section{PATHS OF TRANSPORT TO THE BIOSPHERE}

K. Kennedy, Science Applications, Inc.

\section{PATHS}

The group considered the possible transport paths to the biosphere through the hydrogeologic system. Considered were:

- Low-permeability rock surrounding the waste repository;

- Man-induced fractured rock in the vicinity of the repository storage and access construction areas;

- Higher permeability zones such as the interlayers at some distance above and/or below the lower permeability repository rock;

- Exploration/development boreholes that may be improperly sealed;

- Access shafts and tunnels which may be improperly sealed;

- Faults or other similar geologic structures which may cross and represent potential pathways through several basalt flow units.

It was agreed that definite prioritization of the pathways themselves was not feasible at this point. The committee felt that it was possible, however, to give priority to the necessity for definition and understanding of the various potential pathways.

\section{LOW-PERMEABILITY AND MAN-INDUCED FRACTURE SYSTEM}

A basalt repository may be located in low-permeability rock. As such, this medium represents the immediate pathway for radionuclide migration from a repository. It may be altered from natural conditions by one or more site-related activities or consequences such as:

- Thermal alteration;

- Fracturing from the natural rock stress/relief;

- Construction-related fracturing.

The deyree of alteration cannot be specteled for a varlety of potential repository characteristics at different sites. The alteration extent at any repository site should be small and should have essentially no consequence on the low-permeability rock pathway from the repository. The low-permeability rock should not be compromised by alteration mechanisms so that it ceases to be a major barrier to transport between the repository and the higher permeability zones. 
The basalt rock surrounding a possible repository ideally will have a low hydraulic conductivity and low vertical and horizontal potential energy gradients across it. The committee suggested that absolute values cannot be arbitrarily assigned to these parameters as acceptable criteria. Pathway definition and travel time to the biosphere are more realistic parameters for establishing an acceptable set of criteria related to the repository rock system. The physical and hydrodynamic characteristics of the low-permeability rock surrounding a repository should be investigated and understood in more detail than any other potential pathways surrounding a specific containment site. In general, the detail of hydrogeologic knowledge can probably decrease as a function of distance from the repository, although all attempts should be made for as complete knowledge of the subsurface environment as is necessary.

\section{EXPLORATORY/OEVELOPMENT BOREHOLES}

The existence of repository-related or nonrelated resource exploratory boreholes in a proposed repository site did not, in the opinion of the committee, preclude further consideration of such a site for a nuclear waste repository. In the Hanford basalt terrains, which we considered in particular, there has not been a history of previous deep drilling for resource exploration. Resource exploration in other areas of the Columbia Plateau also. involves only a limited number of deep holes.

Information on the location and depth of deep holes constructed for the purpose of the Basalt Waste Isolation Program is on file. For these reasons, it is believed the locations of deep boreholes can be adequately documented and, where appropriate, remedial actions taken to either reenter and replug or reopen the borehole for use.

Three types of categories of repository-related holes are:

- Shallow;

- Near-repository depth;

- Deeper than repository depth.

Consideration of each of these types of holes is important to the assessment of the suitability of a specific site for a repository. Shallow holes are not expected to be effective radionuclide pathways to the biosphere from a deep repository. The other types of holes, namely near-repository depth and deeper than repository depth. could be 
effective pathways if not adequately sealed. The committee concluded that adequate borehole plugging technology can be developed prior to sealing of the repository. Demonstration of such technology along with tested application procedures are needed in the near future.

The committee concluded that information gathered from deep holes cannot be adequately obtained in any other manner and, thus, deep holes are needed. Permanent sealing of such holes should be delayed until such time as adequate sealing technology and procedures are demonstrated. Similarly, any non-repository-related exploration or resource development holes penetrating into or through the area of a repository should he. resealed using the same technology and procedures.

\section{REPOSI TORY ACCESS SHAFTS}

Without an effective seal, this path has a high potential for radionuclide transport to the biosphere. The committee concluded that an adequate basis exists for development and testing of the technology needed within the near future. Apart from a tested technology, a thorough set of procedures and checking will also be needed to assure an acceptable seal. The technology for adequate sealing should be available approximately 40 to 60 years prior to the actual application event at any repository site.

The point was brought out that adequate measures will be needed during the operation of the repository to prevent possible contamination from reaching the surface through the open shaft. Such measures are likely to include an air lock.

The committee concluded that the shaft-sealing problem appears solvable from the standpoint of the hydrologic pathway. With expected technology development and adequate application of such technology, the shaft seal should not in the future be considered as a high-risk path to move radionuclides to the environment.

\section{TRANSPORT PROCESSES}

The committee listed the following transport processes as to their relative importance:

- Convection;

- Sorption and other chemical interaction;

- Hydrodynamic dispersion; 
- Radioactive decay, including chain decay;

- Gas phase transport;

- Molecular diffusion.

It was agreed, for a repository in the Columbia River basalts, that ground water movement was of prime importance; hence, the emphasis upon convective transport through the ground water flow path. It was suggested that the effect of thermally induced convection currents caused by the radioactive waste should be examined. If ground water convective transport could be shown to be slow enough to assure adequate containment, consideration of other transport processes may not be necessary. One possible exception to this is the case of dispersion which would tend to cause the waste to reach the biosphere sooner than predicted from a simple convection analysis. However, dispersion would also cause the waste to be in lower concentrations upon arrival. It was also pointed out that, for practical field applications, the major component of dispersion is actually unknown smali-scale convection. However, even if the best available data show that ground water velocity is low enough to achieve acceptable containment, uncertainty in our knowledge and predictability of the convective flow is likely to make other transport processes, primarily sorption, important considerations as factors of safety.

Sorption is an important retardation factor and, as such, could be a key transport process.

Dispersion was considered a spreading phenomenon, rather than a term in the classical solute transport equation. Controversy remains as to its true meaning in a mathematical sense. However, spreading phenomena are real and tend to dilute the waste as it moves with the ground water. Radioactive decay, including chain decay, was placed in fourth position primarily because it is not difficult to determine. Efficient chain decay calculation in a numerical model can be a computer programming challenge, but is not likely an insurmountable one. The decay rate is important in relation to total travel time to the biosphere and is predictable for specific nuclides. Decay chain daughter product chemical interaction with the host rock should be considered in establishing possible travel times to the biosphere. 
Concern was expressed regarding the production of radioactive gases, such as radon, during waste decay. Transport of such gases should be considered. The volume of such gaseous decay products produced should be calculated to obtain a perspective regarding the importance of such phenomena. The question of gas production from radiolysis and/or electrochemical reaction with a canister also needs to be addressed. Pressure buildup from such gas production could create unfavorable driving forces in the repository.

Molecular diffusion was considered to be a relatively minor transport process.

\section{REASEARCH NEEDS}

A standard reference set of rock samples should be made available for geochemical and physical study coordination among different site-specific investigators.

An understanding and definition of the ground water system should be developed to establish the ground water flow path and potential travel time of radionuclides from a repository to the biosphere. Adequate estimates of the key hydrogeologic parameters, such as hydraulic conductivity and effective porosity, should be obtained as a function of horizontal and vertical space and direction. Ground water potential energy gradient information should be determined as a function of space and estimated as a function of time.

Sorption experiments using approprlate fresh and fractured rock should be conducted to determine the retardation of radionuclides along the ground water flow paths.

Nonvertical holes are highly recommended. Fully horizontal holes may be optimum in some instances.

A balanced hydrogeologic data acquisition program should be developed. Some holes should be optimized for obtaining good geochemical samples. This may mean that air rotary holes should be drilled in some instances, as well as core holes.

Age dating the ground water beyond the age current carbon-14 methods needs to be examined and probably improved. Uranium age dating can give age limits, but could prove to be difficult and expensive. Development of rubidium/strontium age dating methods could prove useful. 
Early and often simple scenarios or sensitivity analyses can be useful in putting many problems or perceived problems into perspective. Consequence analysis should be considered as an alternative to assigning hard values and limits to specific pathways.

Tracer tests may be useful for establishing the key ground water parameters for pathway definition and travel velocity. Such tests should be conducted on a site-specific basis.

More regional hydrogeologic studies, such as those evaluating the entire Pasco Basin, should be preliminary to those specific to individual sites.

Examination of the thermal and mechanical alterations created by construction and operation of a repository should be integrated with the hydrogeologic investigation related to site-specific repository rock. 


\section{BARRIERS NEEDED FOR CONTAINMENT}

John Apps, Lawrence Berkeley Laboratory

\section{WASTE FORM}

The main waste form to be stored would be spent unreprocessed fuel. Spent unreprocessed fuel storage would probably be more difficult to store than high-level waste forms. Successful storage techniques for spent unreprocessed fuel would be equally applicable to other waste forms. The principal problem areas requiring attention are outlined below.

\section{Heat Generation}

Spent unreprocessed fuel generates 5 times as much heat output between 10 and $10^{4}$ years and approximately 9 times as much heat output between 10 and $10^{5}$ years as reprocessed waste. Initial temperatures adjacent to the canister are probably greater than 200 to 300 degrees centigrade.

\section{Chemistry}

Limited data are available on spent unreprocessed fuel crystalline phase formation or the nature of leaching by water. It consists primarily of uranium dinxide $\left(1,0_{2}\right)$. There could be a preferential dissolution mechanism of plutonium that could lead to increased concentrations of this element in the repository. This possibility should be looked into. Fission products and transuranics make up approximately 5.0 weight percent of spent unrepronessed fuel. Some fission products could be soluble; e.g., $\mathrm{Cs}_{2} \mathrm{MoO}_{4}, \mathrm{C}_{2} \mathrm{U}_{3} \mathrm{O}_{13}$.

Reactions could also proceed between spent unreprocessed fuel and a zircalloy or stainless steel container to form such phases as in $\mathrm{Cs}_{2} \mathrm{Cr}_{2} \mathrm{O}_{7}$. Spent unreprocessed fuel contains gaseous and mobile elements that need to be controlled (xenon, krypton, radon, iodine-129). The spent unreprocessed fuel cladding will probably not contain the gaseous mobile wastes, since it has a tendency to crack. It is believed that control of the gaseous wastes will not be difficult. Much characterization work on spent unreprocessed fuel has been done (e.g., by Argonne National Laboratory, General Electric Company, and Atomics International). 


\section{Storage}

Spent unreprocessed fuel is brittle. It will probably be stored as intact assemblies, but this needs to be analyzed. There are several options for backfills surrounding the assembly; e.g., helium, glass, particulates (sand), low-melting temperature alloys (lead-antimony, etc.). The emphasis of these options has been for surface storage. Their long-term suitability for subsurface storage needs to be investigated.

\section{Leaching}

Leaching would be a function of surface area, grain boundaries, cracks, inhomogeneities, etc. Further research is needed.

Other waste forms may be more desirable for storage, since secondary barriers would be easier to engineer.

\section{CANISTER}

The present concept is to enclose spent unreprocessed fuel in a container constructed of stainless steel after the spent unreprocessed fuel has cooled in a water pool for 5 to 10 years. The container would serve only to permit handling and temporary storage for 50 years. The possibility of developing a container as a long-term barrier should be investigated.

The discussion below refers to containers with long-term barrier potential.

\section{Function}

Isolation of the waste (i.e., spent unreprocessed fuel) from the ground water.

\section{Candidate Materials}

Hot Pressed Alumina

Advantages

- Highly unreactive, very low corrosion rate.

- Conceivable that container could be designed to last for greater than 106 years. 


\section{Disadvantages}

- Brittle.

- Potential for intergranular corrosion, although not likely. Additional research is advisable.

- Seal is weakest point.

Copper

\section{Advantages}

- Ductile and, therefore, difficult to rupture.

- Overpacks can be engineered that would be chemically stable with respect to copper.

- Occurs stably in the natural environment, particularly in basalts, greenstones, and other low-sulfide environments.

\section{Disadvantages}

- Finite solubility in ground waters and especially in the presence of $\mathrm{HCO}_{3}$ and $\mathrm{NH}_{4}^{+}$. Oxidation state needs to be controlled by rock or overpack.

- Intergranular corrosion (is possible); e.g., in the presence of HS-.

- Uncertainties regarding reactions between spent unreprocessed fuel, filler, and copper.

- Expensive (?).

Other exotic possible canisters with overpacks are nickel steel/ serpentinite and iron/graphite.

Further exploratory research is needed to identify promising container materials.

\section{OVERPACK}

The term "overpack" refers to the material emplaced between the borehole wall and the canister. At present, the spent unreprocessed fuel stored in a repository must be retrievable, and an overpack should be engineered that permits retrieval of the spent unreprocessed fuel. However, long-term storage will require a permanent overpack. The following notes refer to permanent overpacks. 


\section{Functions}

Chemical

- Must absorb leaking nuclides.

- Should control oxidation potential and pH to limit solubility of nuclides.

- Should react chemically with migrating nuclides to minimize solubility.

- Could act as a dehydrating agent, preventing access of water to the waste.

- Should provide corrosion protection to the container.

\section{Physical}

- Should act as a heat transfer medium.

- Should provide stress relief (both static and dynamic).

- Should act as a permeability barrier.

- Should act as radiation shield and permit inspection above the storage well during the initial storage period.

\section{Candidate Materials}

- Layer silicates.

- Zeolites.

- Concrete.

- Eh-pH buffer pairs; e.g., $\mathrm{CuS}_{2}-\mathrm{CuS}, \mathrm{NiO}-\mathrm{FeO}$, etc.

- $\quad$ H buffers; e.g., carbonates.

- Silica-alumina gels.

Materials should be tailored for particular radionuclides considered undesirable. More research needs to be done in the selection of materials.

\section{HOST ROCK}

Subjects addressed in this section relate specifically to basalt.

\section{Function}

- To prevent or minimize leakage of waste to biosphere at greater than maximum permissible concentrations by sorption of radionuclides during ground water transport. 
- To isolate waste from human activity.

- To reduce probability of leakage due to catastrophic events.

- To provide radiation shielding.

- To dissipate heat.

Properties Requiring Optimization

- Minimum permeability.

- Maximum sorptive properties with respect to potentially toxic radionuclides.

- Stability under thermal stress.

- Chemical stability with respect to the overpack (if used).

- Radiation stability.

- Minimum effective ground water velocity.

- Stress field such that incipient fractures remain closed.

- Rock stability under excavation.

- The host rock regional hydrology.

- Distance ground water can travel from site to biosphere.

With site host rock properties characterized, a "predictive" model

can be made to define radionuclide migration from the site given knowledge of the chemistry of radionuclides in that environment.

\section{Advantages}

- Low permeability.

- Potentially enormous sorptive capacity.

- Chemical composition of basalt is more desirable for many waste-rock interactions, in particular, spent unreprocessed fuel.

- Eh buffering.

Disadvantages

- Cannot characterize the host rock adequately over hydrologic regime without impairing hydrologic properties and integrity as a repository.

- Little control over ground water movement through the rock. Most of the water could migrate through few fractures with consequent reduction in effective sorptive surface area. 
- It remains to be proved that the host rock will be a suitable barrier over a time span up to as much as $10^{6}$ years.

- Low permeability prevents convection and, therefore, requires conductive heat flow with associated high-temperature gradients, stress field, and a possibility of container and/or overpack failure.

- Uncertainty of effects of devitrification of glass in basalt (permeability could increase, for example).

- Basalt is low in sulphide content and, therefore, may not retard elements such as technetium and iodine.

There is a possibility of treating the host rock in the storage site vicinity to minimize leakage. This possibility should be explored.

\section{BOREHOLE PLUGGING (TEST HOLES AND SHAFT PLUGGING)}

\section{Functions}

- Reestablish isolation provided by host rock.

- Prevent short path to biosphere.

- Prevent human intrusion.

- Provide additional sorptive material to prevent migration to biosphere via shafts or other openings.

\section{Material Selection Criteria}

- Easily placed in borehole.

- Low permeability can be achieved.

- Adequate bonding to host rock.

- Chemicar stability in given environment.

- Physical stability.

Borehole plugging will be necessary. Further research is needed to characterize and define choice of borehole plugging material (this is urgent).

\section{CONCLUSIONS}

Leakage should not exceed maximum permissible concentrations to the biosphere. We can do this after we define parameter containment such that there is no leak into relative parts of the biosphere. 
Barriers are going to be needed. At present, the principal barriers that hold the most promise are canisters and overpacks. Because there is no option at present to choosing the waste form and the host rock barrier, it is uncertain which will be most important. Canister and overpack barriers should be investigated.

A minority concern was expressed about the apparent emphasis in the Group 2 discussion on engineered barriers for long-term isolation. The minority felt that engineered barriers may have a significant impact during operational time scales, or perhaps during the initial "hundreds of years" after emplacement. However, for longer time periods, the primary isolation barrier which needs to be understood, according to the minority, is the host rock/hydrologic system, not engineered canister or "overpack."

The concept of storage of spent unreprocessed fuel in a subsurface repository appears to place more stringent requirements on storage conditions than on other high-level waste forms.

Not enough is known regarding the spent unreprocessed fuel crystalline phase formation and its leaching characteristics to predict its leaching behavior under waste storage repository conditions. The possibility of plutonium concentrating to criticality levels during leaching should be investigated.

The release of gaseous constituents from spent unreprocessed fuel is not considered to be a major problem at this time.

There is some question regarding the long-term stability of fuel rod assemblies when surrounded by selected filler materials.

Because of the difficulties attending the storage of spent unreprocessed fuel, research on high-level waste product forms should be continued, because such forms may make easier the design and engineering of secondary barriers.

Current activities in the United States concerning canister design are limited to canisters whose function is to permit short-term (approximately 50 years) handling and storage. There is considerable promise for further research into canister materials and design for long-term containment or isolation of radionuclides (i.e., approximately $10^{6}$ years). 
There is a need for further research into selection and design of overpack materials for long-term containment of radionuclides. Opportunities for the design of an effective overpack barrier are promising.

It would be desirable to engineer an overpack that would permit short-term retrieval, as well as long-term isolation of waste.

Considerable uncertainties exist regarding the choice of borehole plugging material. Further research is needed in this area.

Adequate characterization of the repository host rock as a barrier to radionuclide migration could prove so difficult that exclusive reliance on the host rock may be impossible.

It is clear that a multiple barrier approach will be required for the subsurface storage of spent unreprocessed fuel or high-level waste. If spent unreprocessed fuel is to be the chosen material for disposal, emphasis on the selection and design of canister and overpack materials will be needed in order to make these barriers the first lines of defense against leakage.

The criterion for a sucessful multiple barrier design is that leakage to the biosphere should at no time exceed maximum permissible concentrations. 
R. J. Serne, Pacific Northwest Laboratory

\section{GENERAL COMMENTS}

A definition of time for isolation from the biosphere for nuclear waste cannot be generic. It must be determined from parameters established for each specific site and/or scenario or at least each medium and general site location. The isolation time for each nuclide depends upon the initial concentration and the acceptable dose to man. Considering the specific medium and conditions, a model based on mathematical equations can be established to equate necessary parameters to isolation time. Important parameters identified include:

- Quantity of nuclides in the repository;

- Container lifetime;

- Fluid velocity;

- Path length;

- $K_{d}$ adsorption;

- $K_{d}$ desorption;

- Maximum permissible concentrations at the biosphere;

- Leach rate for each isotope for the assumed waste form.

Some examples of simple equations which can be used to estimate travei times of water are as follows.

One dimensional case (the borehole):

$$
t=\frac{p l}{K_{0} U_{0}}
$$

where

$$
\begin{aligned}
& U_{0}=\text { hydraulic gradient, } \\
& K_{0}=\text { permeability, } \\
& \ell=\text { path length, } \\
& p=\text { porosity, } \\
& t=\text { travel time. }
\end{aligned}
$$


Two-dimensional case (symmetric interbed):

$$
\frac{U_{0} K_{0}}{p l} t=\frac{H_{0}}{U_{0} l} \ln \left(\frac{r_{0}}{l}\right)
$$

where

Ho = hydraulic head,

$r_{0}=$ repository dimension.

The travel time of radionuclides can be related to the travel time of the water by the following equations.

Porous flow:

$$
t \text { nuclide }=\left[t \text { water }\left(1+\frac{B d}{p} K d_{w}\right)\right]
$$

Fracture flow:

$$
t \text { nuclide }=\left[t \text { water }\left(1+\frac{S A}{V} K d_{A}\right)\right]
$$

where

$B d=$ bulk density of porous media,

$\mathrm{p}=$ porosity,

$S A=$ surface area of fracture,

$V=$ volume of fracture,

$K d_{W}=$ weight $K d$ (milliliters per gram),

$K d_{A}=$ surface area $K d$ (milliliters per square meter).

Once the travel time for each isotope is established for transport to the biosphere from a specific repository, we can establish the necessary degree of isolation. If isolation is inadequate, we must either change the dimensions of the natural parameters or improve the engineered parameters. 


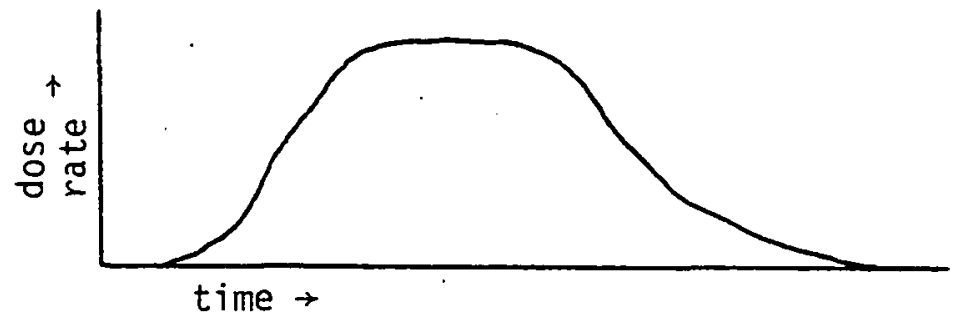

The time of initiation of an adverse dose to the binsphere will he a function of all the above parameters. The initial dosc may be delayed by engineered barriers and/or geometric considerations such that the dose curve will be less than the maximum permissible level throughout all time.

\section{SPECIFIC COMMENTS}

Studies should be conducted in the following order:

- Existing data should be used to develop a simplistic model of the repository area relating travel time to the biosphere with the identified parameters;

- Gather additional data based on information and direction gained from the first model;

- Develop more detailed models based on the additional data;

- Run scenario studies to verify or modify these models;

- Take these results to extrapolate time into the future.

The confidence level of the model will establish the confidence of the prediction of time dependence on:

- Waste form;

- Canister design;

- Overpack;

- llost rock; and,

- Borehole plug.

For the above items, time is quite dependent on the specific medium. Because all but the host rock are engineered, man has considerable control over the time for isolation. Materials scientists feel that, disregarding economic considerations, they can design a container alone that will retain its integrity for a very long time in basalt. There are considerable differences in nuclide leaching rates for different waste 
forms. This will affect time and, again, can within limits be controlled. Cost versus benefits is the major factor for the engineered features. The host rock can be evaluated, but not modified. Time dependence can be established for the initial phases of isolation from laboratory studies. Long-term predictions will be much more difficult. Retrievability need not be considered critical in isolation time considerations for basalt. Apparently all or most of the time considerations relate to creep in salt and thus may not be applicable to basalt. We can be relatively confident about retrievability as long as we elect to keep the repository open and/or as long as the container remains intact (an engineered parameter). 
DISTR IBUTION 


\section{DISTR IBUTION}

Number of

Copies

1

1

1

6

2

1

2

2

2
J. F. T. AGAPITO

AMOCO

G. Servos

ATOMICS INTERNATIONAL

H. C. Weiseneck

BATTELLE-OFFICE OF NUCLEAR WASTE ISOLATION

G. Raines

Library (5)

BECHTEL INCORPORATED

R. A. Langley, Jr.

BOEING COMPUTER SERVICES RICHLAND, INC.

R. W. Nelson

CENTRAL WASHINGTON UNIVERSITY

Department of Geology.

Library

COLORADO SCHOOL OF MINES

F. D. Wang

EASTERN WASHINGTON UNIVERSITY

Department of Geology

Library

GEOSCIENCE RESEARCH CONSULTANTS

J. G. Bond

IDAHO BUREAU OF MINES AND GEOLOGY

M. M. Miller

Library

LAWRENCE BERKELEY LABORÁTORY

J. A. Apps

T. Doe

J. Long 
Number of Copies

LAWRENCE LIVERMORE LABORATORY

L. D. Ramspott

2

LOS ALAMOS SCIENTIFIC LABORATORY

F. E. Goff

K. Wolfsberg

1

OREGON STATE DEPARTMENT OF GEOLOGY AND MINERAL INDUSTRIES

J. D. Beaulleu

2

OREGON STATE UNIVERSITY

Department of Geology

Library

4

PACIFIC NORTHWEST LABORATORY

L. L. Ames

J. R. Raymond

R. J. Serne

Library

3

THE PENNSYLVANIA STATE UNIVERSITY

M. W. Grutzeck

G. J. McCarthy

B. E. Scheetz

5

SANDIA LABORATORIES

E. H. Beckner

L. R. Hill

R. C. Lincoln

A. E. Stephenson

L. D. Tyler

W. D. Weart

1

SCIENCE APPLICATIONS, INC.

K. Kennedy

1 STANFORD UNIVERSITY

I. Rerrisuri

1

W. K. SUMMERS AND ASSOCIATES 
Number of

Copies

1

TERRATEK

M. P. Board

4

U. S. ARMY CORPS OF ENGINEERS

Seattle District Geologist

Seattle District Librarian

Walla Walla District Geologist

Walla Walla District Librarian

1

U. S. ARMY-YAKIMA FIRING CENTER

W. R. Dietderich

$\cdot 1$

U. S. BUREAU OF MINES

J. W. Corwine

1

U. S. BUREAU OF RECLAMATION

D. Newmann

U. S. DEPARTMENT OF ENERGY-ALBUQUERQUE OPERATIONS OFFICE

D. T. Schueler

2

U. S. DEPARTMENT OF ENERGY-COLUMBUS PROGRAM OFFICE

N. E. Carter

J. 0 . Neff

5

U. S. DEPARTMENT OF ENERGY-HEADQUARTERS
C. R. Cooley
M. W. Frei
C. H. George
C. A. Heath
o. L. Vieth

U. S. DEPARTMENT OF ENERGY-NEVADA OPERATIONS OFFICE

R. M. Nelson

U. S. DEPARTMENT OF ENERGY-RICHLAND OPERATIONS OFFICE

T. A. Bauman (4)

R. B. Goranson

A. E. Lassila

B. L. Nicoll

D. J. Squires

$F$. R. Standerfer 
Number of

Copies

5

U. S. GEOLOGICAL SURVEY

C. Collier

W. W. Dudley, Jr.

D. P. Sapik

R. Schneider

D. A. Swanson

2

UNIVERSITY OF IDAHO

Department of Geology

Library

2

UNIVERSITY OF OREGON

Department of Geology Library

4

UNIVERSITY OF WASHINGTON

S. D. Malone

S. W. Smith

Department of Geology

Library

1

VANDERBILT UNIVERSITY

F. L. Parker

WASHINGIUN PUBLIC POWER SUPPLY SYSTEM, INC.

D. D. T1115on

WASHINGTON STATE DEPARTMENT OF ECOLOGY

P. M. Grimstad

H. H. Tanaka

Library

WASHINGTON STATE DEPARTMENT OF NATURAL RESOURCES

v. E. Livingston

Library

WASHINGTON STATE UNIVERSITY

Department of Geology

Library

1

WASTE ISOLATION PILOT PLANT

L. Hill 
Number of

Copies

1

2

A. C. WATERS

WESTERN WASHINGTON UNIVERSITY

Department of Geology Library

2

WESTINGHOUSE WIPP PROJECT

R. C. Mairson

5

WRIGHT STATE UNIVERSITY

B. H. Richard

64

ROCKWELL HANFORD OPERATIONS

R. C. Arnett

H. Babad

R. L. Biggerstaff

D. J. Brown

J. A. Caggiano

D. J. Cockeram

R. W. Cross

T. A. Curran

R. A. Deju (2)

H. B. Dietz

G. C. Evans

K. R. Fecht

M. R. Fox

R. E. Gephart

R. J. Gimera

M. G. Jones

A. D. Krug

R. D. Landon

R. K. Ledgerwood

J. T. Lillie

$P$. E. Long

J. T. Meyer

C. W. Myers

S. M. Price

W. H. Price

M. J. Smith

R. T. Wilde

BWIP Library (30)

Document Control (4)

Records Retention Centers (2) 
RHO-BWI -LD-14

APPENDICES 
APPENDIX A

\section{LIST OF PARTICIPANTS}

L. L. Ames

Pacific Northwest Laboratory

Post Office Box 999

Richland, Washington 99352

\section{J. A. Apps}

Lawrence Berkeley Laboratory

University of California

Berkeley, California 94720

R. C. Arnett

Rockwell Hanford Operations

Post Office Box 800

Richland, Washington 99352

M. P. Board

Rockwell Hanford Operations

Post Office Box 800

Richland, Washington 99352

R. A. Deju

Rockwell Hanford Operations

Post Office Box 800

Richland, Washington 99352

T. Doe

Lawrence Berkeley Laboratory

University of California

Berkeley, California 94720

W. W. Dudley, Jr.

Water Resources Division

U. S. Geological Survey

Post Office Box 25046 (MS 416)

Denver Federál Center.

Lakewood, Colorado 80255

\section{G. C. Evans}

Rockwell Hanford Operations

Post Office Box 800

Richlland, Washington 99352

R. E. Gephart

Rockwell Hanford Operations

Post Office Box 800

Richland, Washington 99352

M. W. Grutzeck

Rockwe 11 Hanford Operations

Post Office Box 800

Richland, Washington 99352
L. R. Hill

Sandia Laboratories

Post Office Box 5800

Albuquerque, New Mexico 87115

K. Kennedy

Science Applications, Inc.

Post Office Box 2457

Santa Fe, New Mexico 87501

R. C. Lincoln - 5338

Sandia Laboratories

Post Office Box 5800

Albuquerque, New Mexico 87115

J. Long

Lawrence Berkeley Laboratory

University of California

Berkeley, California 94720

G. J. McCarthy

Materials Research University

The Pennsylvania State

University

University Park, Pennsylvania 16802

J. T. Meyer

Rockwe 11 Hanford Operations

Post Office Box 800

Richland, Washington 99352

C. W. Myers

Rockwe 11 Hanford Operations

Post Office Box 800

Richland, Washington 99352

R. W. Nelson

Boeing Computer Services

Richland, Inc.

Post Office Box 300

Richland, Washington 99352

S. M. Price

Rockwell Hanford Operations

Post Office Box 800

Richland, Washington 99352

G. Raines

Raines Consulting Inc.

1016 Amberly Place

Columbus, Ohio 43220 
List of Participants (continued)

J. R. Raymond

Pacif ic Northwest Laboratory

Post Office Box 999

Richland, Washington 99352

B. H. Richard

Rockwe 11 Hanford Operations

Post Office Box 800

Richland, Washington 99352

D. P. Sapik

U. S. Geological Survey-

Water Resources Division

Tacoma District Office

Tacoma, Washington 98402

B. E. Scheetz

Materials Research Laboratory

The Pennsylvania State University

University Park, Pennsylvania 16802

R. J. Serne

Pacific Northwest Laboratory

Post Office Box 999

Richland, Washington 99352

W. K. Summers

W. K. Summers and Associates

Post Office Box 684

Socorro, New Mexico 87801

H. H. Tanaka

Washington State Department of Ecology

Southwestern Washington Regional Headquarters

Olympia, Washington 98504 


\section{APPENDIX B}

AGENDA

THURSDAY, JUNE 22, 1978

8:00 a.m. to Noon - Lunch Room

Session I - Introduction

8:00 - 8:30 The Basalt Waste Isolation Program

8:30 - 8:50 Program to Assess Hydrologic Isolation

$8: 50-9: 10$

$9: 10-9: 30$

The Ground Water Modeling Program

Development of New Downhole Testing

Procedures

9:30 - 9:50 Multi-Barrier Approach to Waste Isolation

9:50 - 10:10 Near-Field Waste/Basalt Interaction

10:30 - 10:50 Far Field Waste/Basalt Interaction

10:50 - 11:10 Thermodynamics of Waste/Basalt Interaction

11:10 - 11:30 Borehole Plugging Program

11:30 - 11:50 The Borehole Environment

Session II

Group 1 - Paths of Transport to the Biosphere - Library

- Path Definition

- Relative Importance

- Transport Process

- Relative Importance

- Research Needed

Leader

Moderator

- Keith Kennedy, Science Applications, Inc.

Participants - Wes Myers, Rockwell Hanford Operations Lloyd Ames, Pacific Northwest Laboratory Roy Gephart, Rockwell Hanford Operations Jane Long, Lawrence Berkeley Laboratory Dave Sapik, U. S. Geological Survey Barry Scheetz, The Pennsylvania State University Les Hill, Waste Isolation Pilot Plant
R. A. Deju

R. E. Gephart

R. C. Arnett

T. Doe

M. W. Grutzeck

G. J. McCarthy

R. J. Serne

J. A. Apps

G. C. Evans

B. E. Scheetz 
Session II (continued)

Group 2 - Barriers Needed for Containment - Conference Room

- Waste Form

- Canister

- Overpack

- Radionuclides to Contain

- Host Rock

- Quality of Entrained Fluid

- Engineered Barriers

- Borehole Plug

Leader - John Apps, Lawrence Berkeley Laboratory

Moderator - Jack Meyer, Rockwell Hanford Operations

Participants - Greg McCarthy, The Pennsylvania State University.

George Evans, Rockwell Hanford Operations

Tom Doe, Lawrence Berkeley Laboratory

Sue Price, Rockwell Hanford Operations

Harry Tanaka, Washington State Department of Ecology

Richard Lincoln, Nevada Test Site

William Dudley, U. S. Geological Survey

Group 3 - Time of Isolation from the Biosphere for Each Radioactive Isotope Lunch Room

- Waste Form

- Radionuclides

- Snrption

- Thermal Loading

- Minimum Permissible Concentration

- Borehole Plug Life

Leader = Jeff Serrié, Pacific Nurthwest Laburatory

Moderator - Ben Richard, Rockwell Hanford Operations

Participants - Kelly Summers, W. K. Summers and Associates

Mike Grutzeck, Rockwell Hanford Operations

Bill Nelson, Boeing Computer Services Richland, Inc.

Mark Board, Rockwe 11 Hanford Operations

John Raymond, Pacific Northwest Laboratory

Gil Raines, Office of Waste Isolation, Battelle-Columbus 
FRIDAY, JUNE 23, 1978

8:00 a.m. to Noon - Lunch Room

Session III - Recommendations and Discussions

- Introduction

- Group I Conclusions

- Group II Conclusions

- Group III Conclusions

- Discussion

Introduction

Group I Leader

Group II Leader

Group III Leader

Discussion
8:00 a.m. to 8:15 a.m. - Raul Deju

$8: 15$ a.m. to $8: 45$ a.m. - Keith Kennedy

8:45 a.m. to $9: 15$ a.m. - John Apps

9:15 a.m. to $9: 45$ a.m. - Jeff Serne

10:15 a.m. to 11:30 a.m. - All Participants 